\title{
Computer Application to Estimate PVT Conditions in Oil Wells in the Ecuadorian Amazon
}

\author{
Paulo Escandón-Panchana ${ }^{1,2^{*}}$, Fernando Morante-Carballo ${ }^{2,3}$, Gricelda Herrera-Franco ${ }^{1,2}$, Edwin Pineda ${ }^{4}$, Jonathan \\ Yagual $^{1}$ \\ ${ }^{1}$ Facultad de Ciencias de la Ingeniería, Universidad Estatal Península de Santa Elena (UPSE), Avda. Principal La Libertad- \\ Santa Elena, La Libertad 240204, Ecuador \\ ${ }^{2}$ Escuela Superior Politécnica del Litoral, ESPOL, Geo-Recursos y Aplicaciones GIGA, ESPOL Polytechnic University, \\ Campus Gustavo Galindo Km 30.5 Vía Perimetral, P.O. Box 09-01-5863, Guayaquil 090150, Ecuador \\ ${ }^{3}$ Escuela Superior Politécnica del Litoral, ESPOL, Facultad de Ciencias Naturales y Matemáticas, Centro de Investigaciones y \\ Proyectos Aplicados a las Ciencias de la Tierra (CIPAT), ESPOL Polytechnic University, Campus Gustavo Galindo Km 30.5 \\ Vía Perimetral, P.O. Box 09-01-5863, Guayaquil 090150, Ecuador \\ ${ }^{4}$ Best Energy S.A. Av. Amazonas 1014 y Naciones Unidas 170135, Quito, Ecuador
}

Corresponding Author Email: pcescandonp@ hotmail.com

https://doi.org/10.18280/mmep.080507

Received: 16 March 2021

Accepted: 13 August 2021

\section{Keywords:}

computer application, mathematical correlations, physical properties of oil, PVT estimate

\begin{abstract}
A reservoir behaviour's characterisation is determined by analysing the fluids' physical properties, reported in Pressure, Volume and Temperature (PVT) tests. These tests are performed in the laboratory or are estimated by mathematical correlations with the well's basic properties. The eastern basin of Ecuador is considered a hydrocarbon zone, and the analysis of the physical properties of the fluid from oil wells is essential. The aim is to develop the PVTTESTSYSTEM software to estimate PVT conditions when there are no laboratory tests. The study methodology is based on (i) Compilation of 10 PVT laboratory tests of oil wells in the eastern basin of Ecuador; (ii) Analysis of mathematical correlations; (iii) Development of the PVTTESTSYSTEM software, with the wells' initial conditions' input, selecting the mathematical correlation and estimation of results, based on the relationship of the properties of oil and gas; iv) Comparison of data obtained by laboratory tests and PVTTESTSYSTEM software reports. The software used with a graphical interface presents a registration and login platform and five modules that allow: inserting company and field data, initial oil well data, selecting correlations, calculating PVT properties and generating a graphic report. The results show that the mathematical correlations that estimate PVT properties were systematised, which approximate the laboratory tests' real results. The approximation of the calculated results with the actual results establishes a high confidence level for the PVTTESTSYSTEM software.
\end{abstract}

\section{INTRODUCTION}

In the study of a reservoir, petroleum engineering techniques are necessary, together with the information provided by geology, geophysics and petrophysics, to quantify the reserves and identify production mechanisms that predict a reservoir's behaviour [1-4].

The PVT analysis reflects the behaviour of the fluids in a reservoir [5]. PVT properties are measured experimentally by laboratory tests; if they are not available, they are carried out through simulations with computer applications or computer systems, determining the fluid's volumetric properties and its variation with pressure and temperature. This characterization is carried out through software packages, using algebraic equations or mathematical correlations that record specific PVT values [2, 6-9]. PVT correlations depend on the sectors or oil fields in different world regions, leading to studies or analyses of particular fields [10].

PVT analysis is necessary for understanding test results, gaining meaningful insights from oil wells [11]. This analysis establishes the correlation between in situ pressure and volume, chemical components, physical properties such as density, compressibility and viscosity, temperature effects, gas to oil ratio (GOR) [12], the specific gravity of the gas, the bubble point's pressure-volume factor [13]. PVT properties are a function of the reservoir's temperature and pressure and vary considerably depending on the concentration of chemical compounds of different hydrocarbon types. For black oil, they are required for reservoir, production and surface facility calculations, which predict the behaviour of oil fields [14].

When experimental PVT reports are not available, mathematical correlations used in decision-making in the oil industry. When a new reservoir considered, for which there is no laboratory PVT report, they performed. Approximations through mathematical correlations: Standing, Glasso, AlMarhoun, Vásquez and Beggs, Beal, Petrosky and Farshad [2, $8,15,16]$. The systematisation of empirical correlations brings advantages in terms of time and economic factors in studying a reservoir [17].

PVT simulators predict reservoir fluid's physical properties with varying degrees of precision, which are essential tools during reservoir evaluation. This software's accuracy is based on comparing experimental results from simulations and laboratory PVT tests [3, 18]. Simulations obtained from 
computer programs are consistent with data extracted from laboratory test fluid samples, determining a faster and more reliable fluid characterization [8]. In the United Arab Emirates black oil reservoir characterization investigations, using the equation of state to determine the PVT behaviour of crude oil, the results show the excellent agreement of the PVT properties using state equation compared to laboratory tests [19]. The estimates of different PVT software packages are generally consistent, as is the case of the PVT Sim software, used to characterize black oil's behaviour from the Norwegian North Sea, presenting a margin of error of $5 \%$, considered an almost perfect predicted data [6]. The study reported by Aplin et al. [20] reflects the use of a PVT simulation that determines the physical properties of fluids such as viscosity, saturation pressure, gas-oil ratio, density, and molar volume; This study marked an overall accuracy in the prediction of the North Sea black oil PVT data. Liu et al. [21] used the PVT Sim software to determine the composition, and physical properties of black oil from the Lunnan Low Uplift sector of the Tarim basin in western China required calculations of compression, density, saturation, pressure and temperature, reporting accurate data in compositional analysis of crude. Other research indicates using an efficient black oil PVT data prediction algorithm based on brine PVT and black oil PVT data [22]. In an analysis of oil reservoirs belonging to the Gulf of Mexico, PVT data sets were generated, using a simple program under the Microsoft Excel office suite, reporting functional results, thus obtaining the study's correlations [7]. Another PVT property prediction model, based on the analysis of oil from wells from different Colombian oil basins, uses the statistical software Statgraphics Centurion XVI, which allows selecting the empirical correlations that best fit the initial conditions of Colombian oil wells [23]. Predictive models for Nigerian crude oil PVT properties were developed based on multivariate linear regression techniques using the $R$ programming language. According to the data obtained by the correlation coefficient for the bubble pressure, volumetric oil factor and GOR properties, the study results are acceptable [24]. In Pakistan, for predicting PVT correlations, artificial neural networks were used to predict the bubble pressure, volumetric factor, and viscosity of the oil, with the lowest error results in calculating the properties' correlations [10]. The same applies to the estimation of PVT properties of oil fields in the Middle East, Malaysia and the North Sea, where they used artificial neural networks to predict bubble pressure and oil's volumetric factor [4]. In an investigation to predict PVT properties of crude oil, an algorithm called IntelliPVT, developed in MATLAB and Python, was proposed, which shows accurate results in reservoir characterisation through PVT properties such as bubble pressure, volumetric factor, GOR, viscosity and compressibility of the oil [25].

Ultimately, PVT simulators predict the physical properties of reservoir fluids with many degrees of precision, based on the nature of the fluids and the prevalence of their conditions $[1,18]$.

Oil exploitation in Ecuador began at the beginning of the 20th century with Anglo Ecuadorian Oilfields Limited [26]. An oil country since the 1970s and its economy has based on this resource [27, 28]. For this reason, one of the essential computer applications is the one that focuses on the calculation of the PVT conditions in an oil field, for the oil of eastern Ecuador, which allows us to ask ourselves the following question: Is it possible that a computer application, orderly and systematic, allows estimating statistically with an appropriate approximation the properties of PVT, based on initial conditions of a deposit in eastern Ecuador?

In the Oriente basin's oil wells, physical characteristics of fluids and reservoirs such as oil density, bubble pressure, GasOil ratio (GOR), volumetric factor, compressibility, and viscosity of oil gas are measured with some frequency [1, 29]. These properties are obtained from the oil well's initial conditions and through the analysis of empirical correlations. Those that fit the reservoir's real behaviour, selected for a black oil model probably called ordinary oil, it is mainly characterized by the gas-oil ratio of $2 \mathrm{PCN} / \mathrm{BN}$ (Normal cubic feet / Normal barrels), gravities up to $45^{\circ} \mathrm{API}$ and volumetric factors below $2 \mathrm{BY} / \mathrm{BN}$ (Reservoir barrels / Normal barrels).

This work develops a PVTTESTSYSTEM computer application, using an algorithm to estimate PVT correlations in a sample of 10 wells in eastern Ecuador, which helps decision-making in the different petroleum engineering processes. PVTTESTSYSTEM is a software application organised, user-friendly, customisable, and easy to use, which systematises and estimates empirical correlations. It is an interactive, modifiable, applicable, storable and reliable application. Furthermore, it has an information storage platform, which allows the reproduction of empirical correlations applicable to different properties and reservoirs. Accurate readability of information, showing two-dimensional graphs of the relationship between the initial conditions of the well and its different physical properties.

\section{MATERIALS AND METHODS}

Figure 1 shows this research methodology, which is defined in three phases: i) data collection from ten PVT laboratory tests of oil wells in Ecuador's eastern basin. Also, a bibliographic review of empirical correlations carried out. ii) An algorithm was built based on the oil wells' initial conditions, which influenced the PVTTESTSYSTEM software design. iii) With the results reported by the PVTTESTSYSTEM software, a statistical analysis was performed, specifying absolute and relative error percentages, which resulted in data obtained by laboratory tests and application reports considering the fluid's properties.

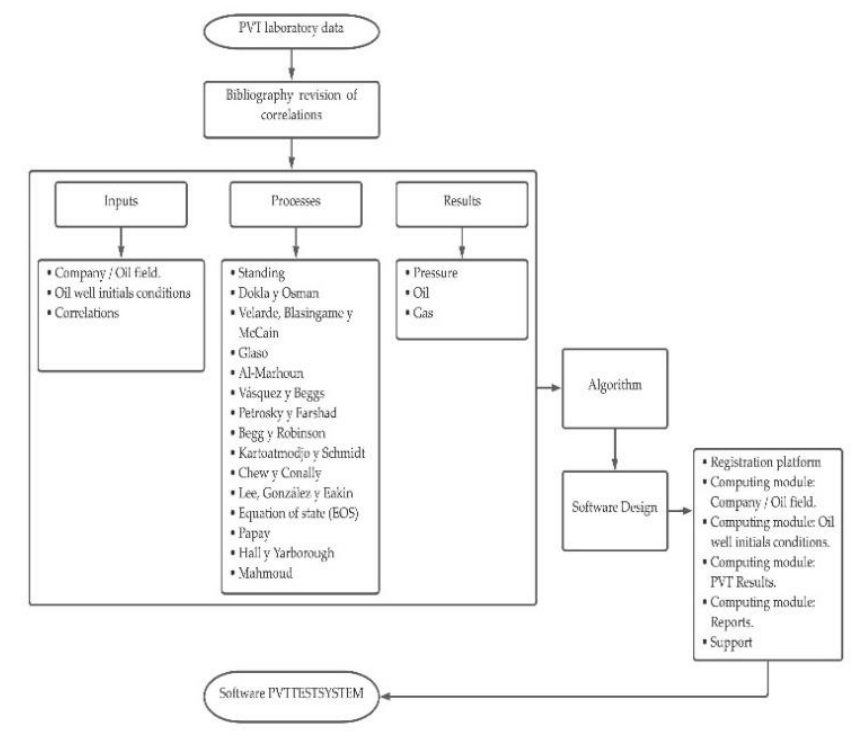

Figure 1. Software methodological procedure 


\subsection{Laboratory PVT test data}

The data used in this study were obtained from the information from the analysis of laboratory PVT fluid samples corresponding to 10 wells in Ecuador's Oriente basin. Table 1 shows the initial conditions of oil wells, such as pressure, temperature, API, solubility, and the gas's specific gravity [1, $7,18,19,25]$.

\subsection{Bibliographic review of empirical correlations}

Mathematical correlations (PVT correlations) used equations obtained from statistical regressions from laboratory field data, formulated mainly to estimate the fluid properties in the reservoir. According to the reservoir fluid's characteristics, these empirical correlations predict PVT properties, such as specific gravity and the crude oil's API grades, such as specific gravity and the crude oil's API grades. The main properties of the fluid that are analyzed are bubble pressure, compressibility, and gas viscosity, among others. Table 2 shows the fluid's main properties and the respective empirical correlations used for the PVT analysis. [1, 23, 3033].

Table 1. Initial conditions of oil wells in the Oriente basin of Ecuador

\begin{tabular}{ccccccc}
\hline $\mathbf{N}^{\circ}$ & Oil well & Pressure (psi) & Temperature $\left({ }^{\circ} \mathbf{F}\right)$ & ${ }^{\circ}$ API & Solubility (SCF/STB) & Specific gravity \\
\hline 1 & Palo Azul-02 & 3289 & 228 & 28 & 379 & 1.342 \\
2 & Palo Azul-02 & 4318 & 233 & 27.2 & 399 & 1.478 \\
3 & Arazá-02D & 2770 & 215 & 31 & 498 & 1.53 \\
4 & Tapi-09 & 3624 & 216.7 & 29.7 & 99.4 & 1.326 \\
5 & Yanaquincha-09 & 2576 & 214 & 19.6 & 196.7 & 0.756 \\
6 & Yuralpa A-01 & 3297 & 175 & 17.1 & 21 & 0.965 \\
7 & Parahuacu-07 & 2150 & 199 & 34.2 & 366 & 0.834 \\
8 & Shushufindi-051 & 2837 & 185 & 24 & 187 & 0.738 \\
9 & Palmar Oeste-01 & 2606 & 200 & 30.9 & 166 & 1.678 \\
10 & Sonia-01 & 2207 & 188 & 23 & 88 & 0.882 \\
\hline
\end{tabular}

Note: Psi: pounds per square inch, ${ }^{\circ} \mathrm{F}$ : Fahrenheit degrees, ${ }^{\circ} \mathrm{API}$ : American Petroleum Institute, SCF/STB: standard cubic foot per stock tank barrel

Table 2. Fluid Properties and Empirical Correlations

\begin{tabular}{|c|c|c|}
\hline Fluid properties & Empirical correlation & $\begin{array}{l}\text { Reference } \\
\text { citation }\end{array}$ \\
\hline \multirow{8}{*}{ Bubble pressure } & Standing & {$[7,31,34]$} \\
\hline & Petrosky \& Farshad & {$[7,31,35]$} \\
\hline & Lasater & {$[31,36,37]$} \\
\hline & Glaso & {$[23,31,38]$} \\
\hline & Al-Marhoun & {$[23,31,39]$} \\
\hline & Dokla \& Osman & {$[23,40]$} \\
\hline & $\begin{array}{c}\text { Velarde, Blasingame y } \\
\text { Mc Cain }\end{array}$ & {$[31,41]$} \\
\hline & Standing & {$[7,34]$} \\
\hline \multirow{3}{*}{ GOR (gas-oil ratio) } & Glaso & {$[31,38]$} \\
\hline & Al-Marhoun & {$[31,39]$} \\
\hline & Petrosky \& Farshad & {$[7,35]$} \\
\hline \multirow{5}{*}{ Oil volumetric factor } & Standing & {$[7,23,34]$} \\
\hline & Glaso & {$[23,31,38]$} \\
\hline & Al-Marhoun & {$[23,31,42]$} \\
\hline & Petrosky \& Farshad & {$[7,23,35]$} \\
\hline & Standing & {$[7,34]$} \\
\hline \multirow{4}{*}{ Compressibility } & Petrosky \& Farshad & {$[7,35]$} \\
\hline & Vásquez \& Beggs & {$[7,23,43]$} \\
\hline & Ahmed & {$[37,44]$} \\
\hline & $\begin{array}{l}\text { Kartoatmodjo \& } \\
\text { Schmidt }\end{array}$ & {$[45,46]$} \\
\hline \multirow{4}{*}{ Dead oil viscosity } & Beal & {$[37,47]$} \\
\hline & Beggs \& Robinson & {$[37,48]$} \\
\hline & Glaso & {$[23,31,38]$} \\
\hline & $\begin{array}{l}\text { Kartoatmodjo \& } \\
\text { Schmidt }\end{array}$ & {$[45,46]$} \\
\hline \multirow{4}{*}{ Satured oil viscosity } & Kartoatmdjo \& Schmidt & {$[45,46]$} \\
\hline & Beggs \& Robinson & {$[37,48]$} \\
\hline & Chew \& Connally & {$[7,37,49]$} \\
\hline & Almehaideb & {$[31,37,50]$} \\
\hline \multirow{3}{*}{$\begin{array}{c}\text { Gas viscosity } \\
\text { Gas volumetric factor }\end{array}$} & Lee, González y Eakin & {$[51,52]$} \\
\hline & Ecuación de estado & [3] \\
\hline & Papay & [53] \\
\hline \multirow{3}{*}{ Gas compressibility factor } & Hall \& Yarborough & {$[44,53]$} \\
\hline & Brill yBeggs & {$[52]$} \\
\hline & Mahmoud & {$[3]$} \\
\hline
\end{tabular}

The main characteristic of the bubble pressure determines the highest pressure when the first gas bubble is released. Reservoir gas is formed by the decrease of pressure in the reservoir that is below the saturation pressure. The particularity of compressibility represents the change in fluid volume concerning pressure changes under isothermal conditions, which occurs during the constant mass depletion test. The gas compressibility factor establishes the dimensionless quantity to correct the gas at very high pressure and temperature, calculated by the fundamental equation of state. The oil's volumetric factor specifies the ratio of the volume of oil to the volume of gas in the reservoir at standard conditions. The gas' Volumetric factor reflects the gas' volume at temperature and pressure at any instant below the bubble pressure, calculated by the composition analysis [18].

The GOR property establishes the relationship between the gas and oil produced. On the other hand, dead oil viscosity is based on the value of the viscosity of gas-free oil at standard conditions, while saturated oil viscosity is the value of the viscosity of crude oil at bubble pressure and reservoir temperature conditions [33].

\subsection{Algorithm design}

The algorithm parameters are determined based on the general characteristics of the empirical correlations' fluid properties. Figure 2 shows the algorithm's structure consisting of three stages: i) inputs, company and oil field, good initial conditions (pressure, temperature, ${ }^{\circ} \mathrm{API}$, solubility, and gas specific gravity); ii) selection and input of correlations, is the processing of data that responds to the evaluation of mathematical correlations, used according to the physical properties of the fluid, empirical correlations (Table 2) and the storage of correlation data for further studies; iii) the results are the oil's ratio properties (bubble pressure, volumetric factor, compressibility, viscosity) and gas (volumetric factor, viscosity, compressibility factor) $[54,55]$. 


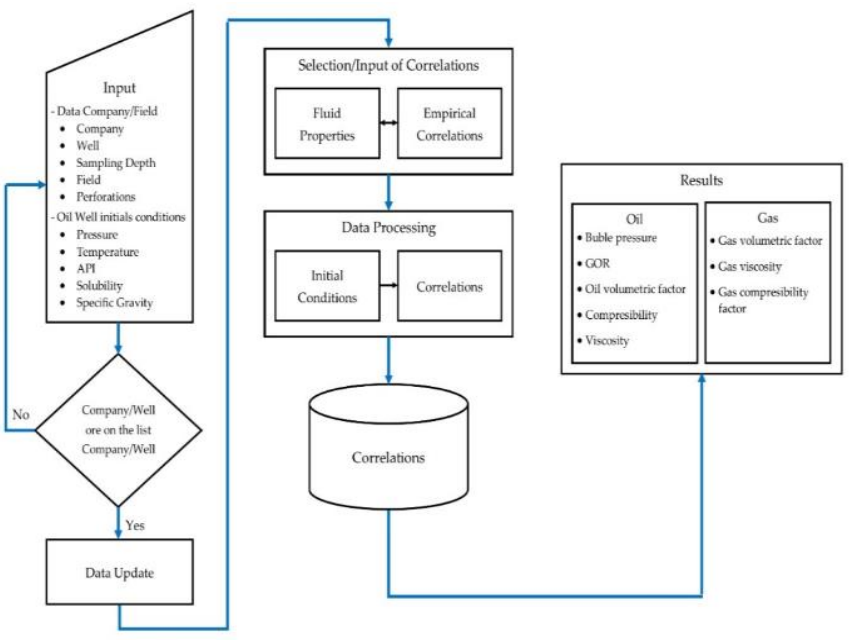

Figure 2. PVTTESTSYSTEM Algorithm

\subsection{PVTTESTSYTEM software design}

For the development of the PVTTESTSYSTEM simulator, the Visual Basic .Net 2019 programming language used, a programming language under a new integrated development environment, allows interactive computer applications with a broader variety of programming resources [56]. The database platform of the PVTTESTSYSTEM application is the SQL Server 2005 manager, the same one that processes large amounts of information and works with relational databases that imply accessibility to data analysis [57]. PVTTESTSYSTEM was developed and illustrated with the empirical correlations shown in Table 2; once the correlation had been systematized, the results corresponding to the fluid's physical properties presented [35].

\subsection{Statistical analysis}

The error analysis was performed on the empirical correlations and the laboratory PVT tests results, projecting a comparison between predictive results (mathematical correlations) and initial results (laboratory tests). This comparison carried out by calculating the absolute and relative errors of each of the correlations used. The correlations with a lower percentage of relative error allow a better understanding and a more significant adjustment in the relationship between the properties of fluids and the empirical correlations, justifying its application in the PVTTESTSYSTEM software $[1,7,15,31]$. The smallest percentage of absolute average error (\% AARE) was determined for the calculations carried out. The appropriate correlation to the fluid properties, according to Al-Zahaby et al. [46], the formula establishes the percentage of absolute error:

$$
\begin{aligned}
& \% \text { AARE } \\
& =\frac{\text { Laboratory PVT }- \text { PVT resultado correlation }}{\text { Laboratory PVT }} \\
& * 100
\end{aligned}
$$

\section{RESULTS}

\subsection{Description of the PVTTESTSYSTEM program}

According to the algorithm used by Lasater [36], the
PVTTESTSYSTEM platform developed, as shown in Figures 3-8, a computer application designed for PVT analysis of black oil that is composed of 5 modules that enable: 1) Window for entering the general data of the company and the oil field; 2) Initial data entry window: pressure, temperature, ${ }^{\circ} \mathrm{API}$, solubility and specific gravity, 3) Selection of empirical correlations for each of the fluid properties; 4) Calculation of the properties of oil and gas fluids through correlations, and 5) Software reports, which depend on the minimum and maximum pressure. In addition to twodimensional graphical reports of the relationship between pressure and fluid properties.

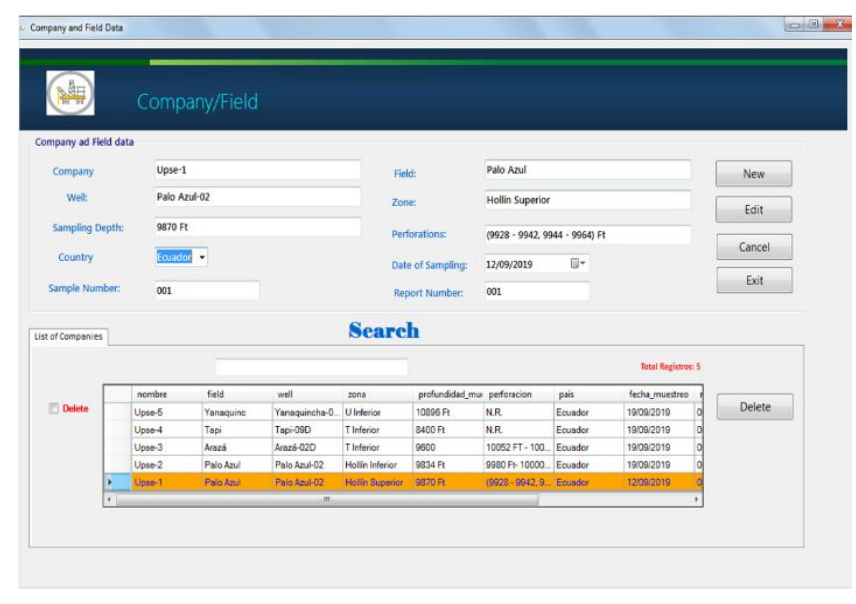

Figure 3. The data entry window for companies and oil fields

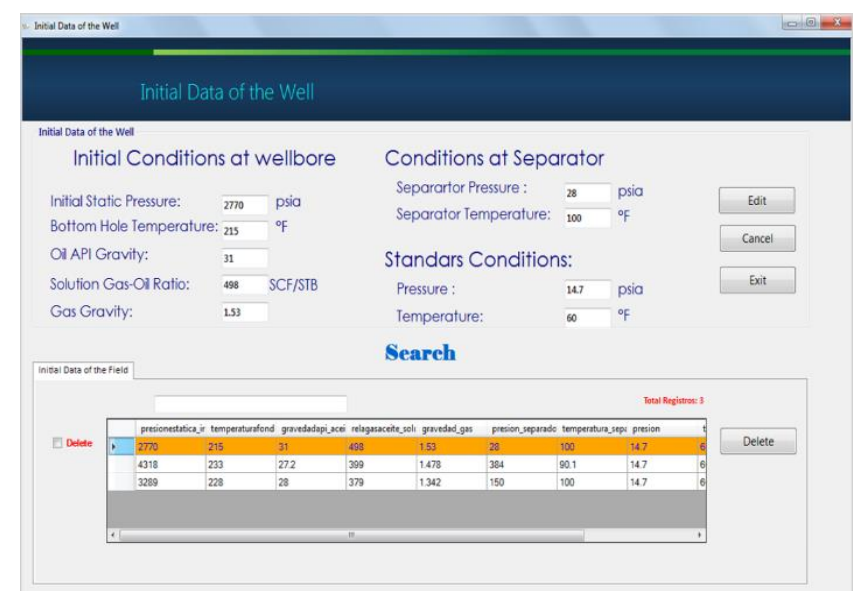

Figure 4. Initial input data from oils wells

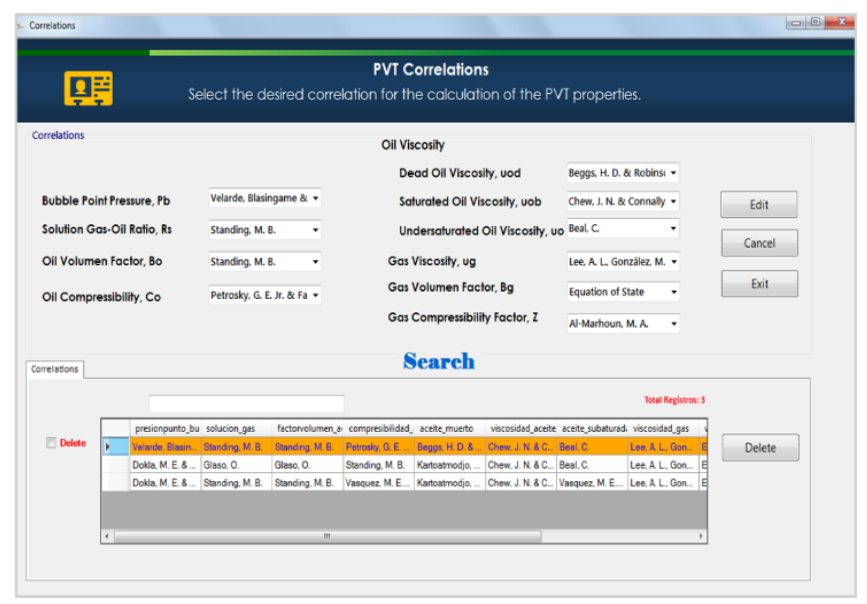

Figure 5. Empirical correlation selection window 


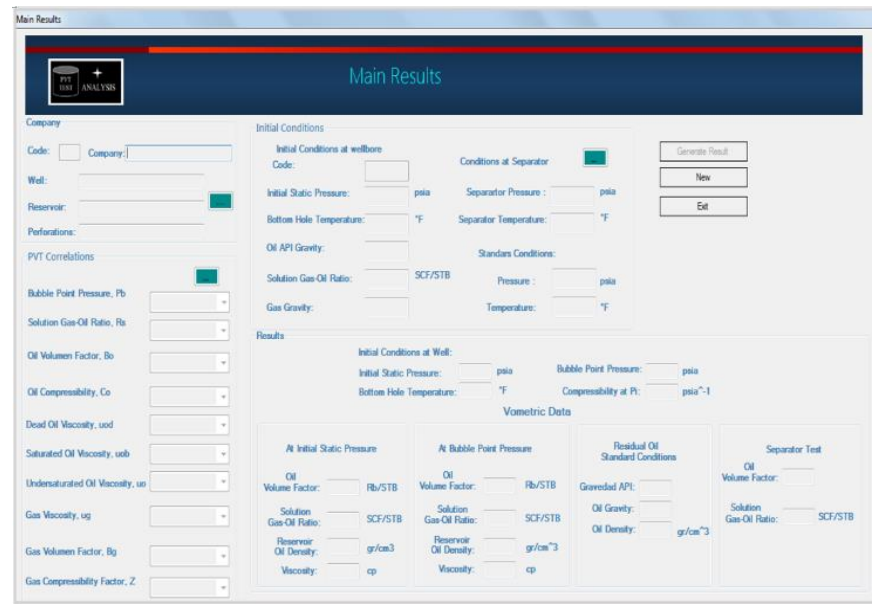

Figure 6. Oil and gas properties main results window

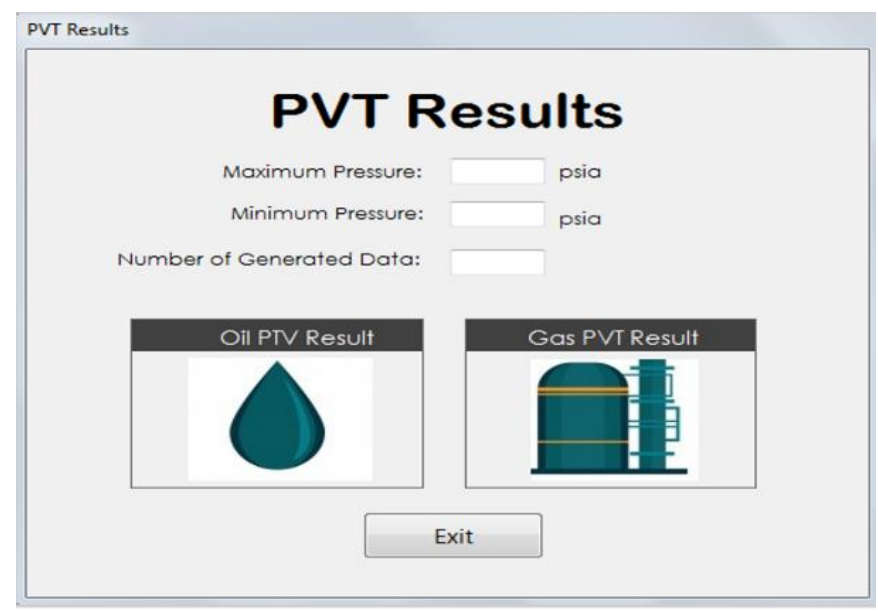

Figure 7. Oil and gas results window

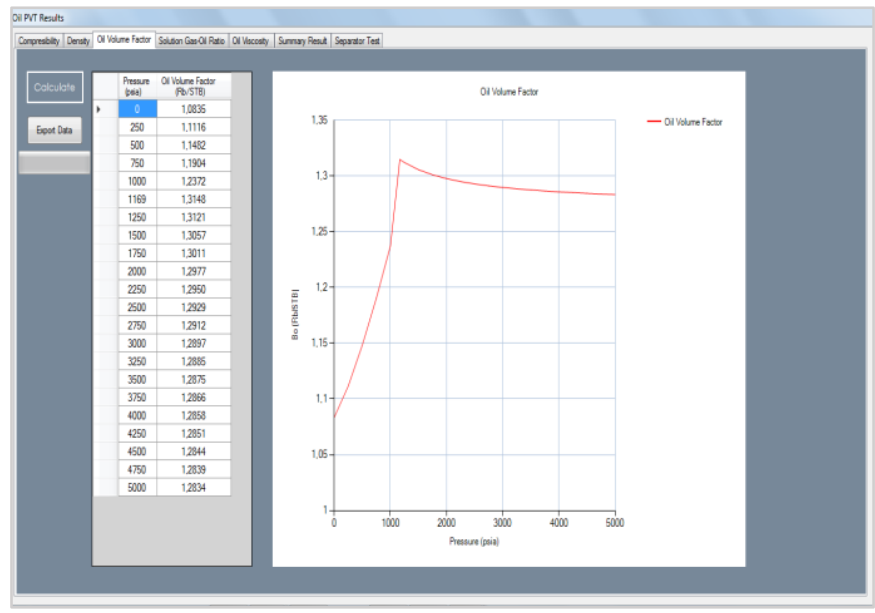

Figure 8. Dimensional reports window (pressure relationship and fluid properties)

\subsection{PVT results in terms of correlation}

\subsubsection{Bubble Pressure}

Table 3 shows the intervals of values of the initial conditions of the ten wells. Table 4 presents the PVTTESTSYSTEM software results concerning the PVT correlations for black oil from the wells' bubble pressure fluid properties.

Table 3. Range of initial conditions of oil wells

\begin{tabular}{cc}
\hline Initial conditions & Intervals \\
\hline Pressure & From 2150,00 to $4318,00(\mathrm{psia})$ \\
Temperature & From 175 to $233\left({ }^{\circ} \mathrm{F}\right)$ \\
${ }^{\circ}$ API & From 17,10 to 34,20 \\
Solubility & From 21,0 to $498,00(\mathrm{SCF} / \mathrm{STB})$ \\
Specific gravity & From 0,74 to 1,68 \\
\hline
\end{tabular}

Table 4. Empirical correlations bubble pressure properties

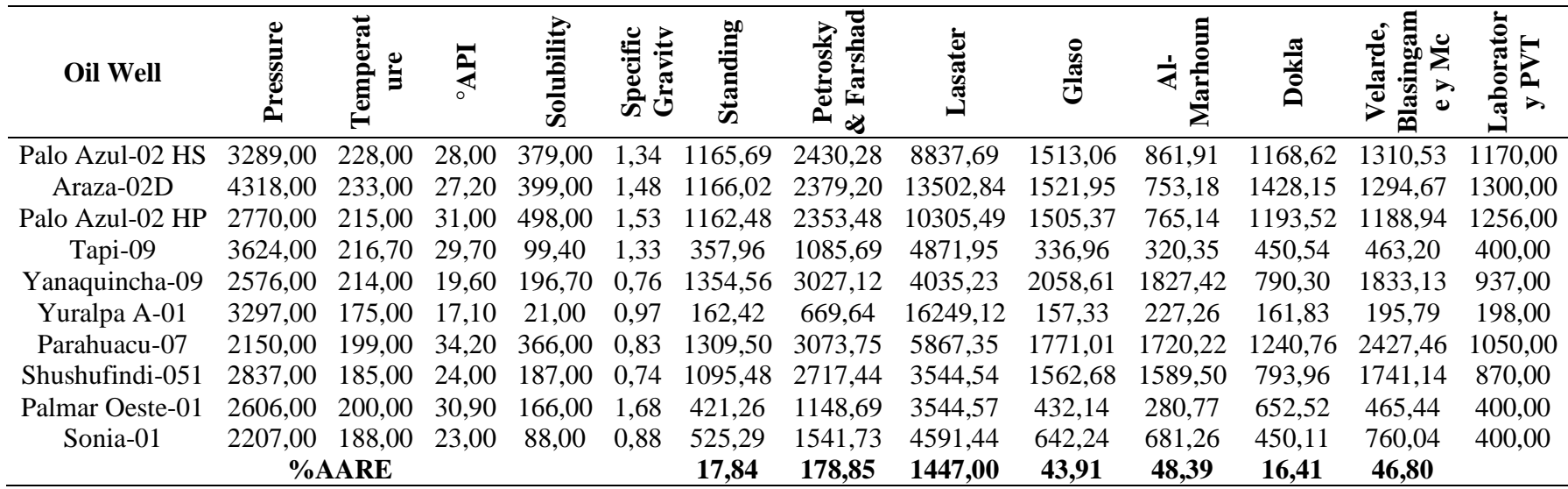

The ranges for each of the initial conditions apply to all properties of the fluid. However, the last column of Table 4 presents the laboratory tests' real values for each of the wells mentioned above. Therefore, the $\%$ AARE of each of the correlations determined, thus being the correlation with the lowest $\%$ AARE for the bubble pressure property of the Dokla \& Osman correlation, followed by the Standing correlation.

Figure 9 shows the relationship between the different initial pressures of oil wells and the empirical correlations' bubble pressure properties. Thus, the Dokla and Osman correlation is the one that is closest to the laboratory test, followed by the
Standing correlation. In contrast, the Lasater correlation is far from the bubble pressure value concerning the laboratory test. All correlations are determined under the same initial well conditions but differ in the estimation parameters, the \%AARE, which indicates the degree of approximation. This difference is highlighted by the Dokla and Osman correlation applicability parameters, concerning bubble pressure which uses a range of 590 to $4640 \mathrm{psi}$ and temperatures from 190 to $275{ }^{\circ} \mathrm{F}$, as opposed to Lasater, which uses bubble pressure from 48 to $5780 \mathrm{psi}$, and temperatures from 82 to $272^{\circ} \mathrm{F}$. 
A
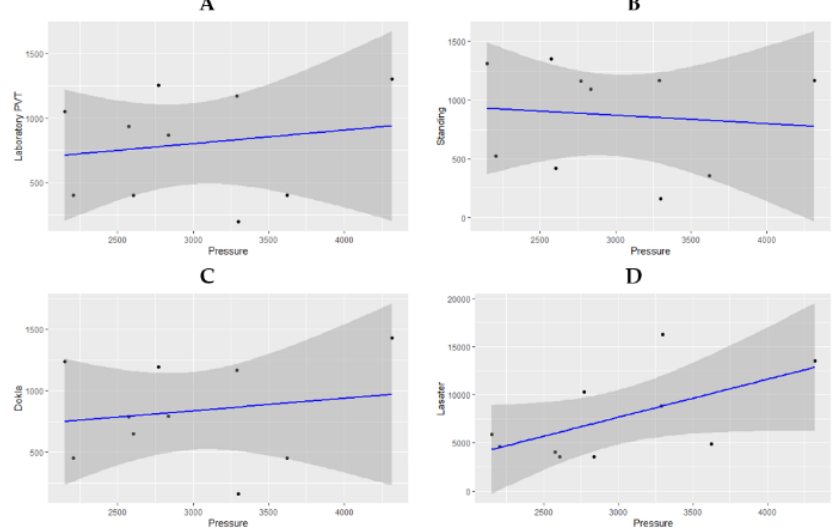

Figure 9. Pressures of oil wells and the empirical correlations' bubble pressure properties. (A) Laboratory test; (B) Standing correlation; (C) Dokla y Osman correlation; (D) Lasater correlation

\subsubsection{Gas-oil ratio (GOR)}
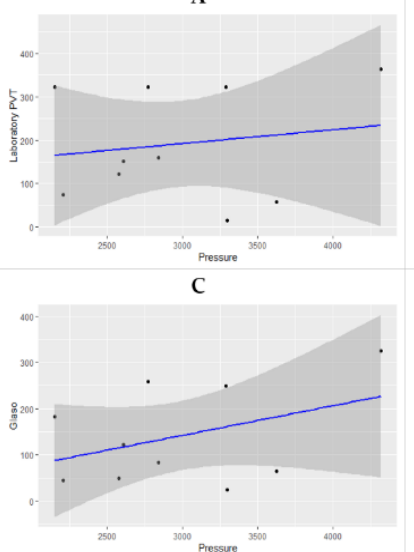

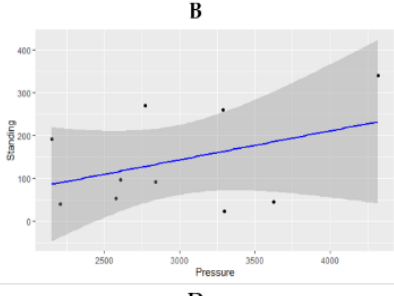

D

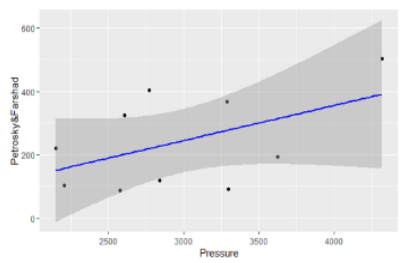

Figure 10. Pressure relationship and GOR properties (gas-oil relationship). (A) Laboratory test; (B) GOR correlation of Standing; (C) Glaso correlation; (D) Petrosky \& Farshad correlation

Table 5 shows the empirical correlations' results (Standing, Glaso, Petrosky \& Farshad) of the GOR property (oil-gas ratio) and the real laboratory tests' results, under the initial conditions reported in Table 3. Therefore, the Standing correlation correlates with the lowest percentage of error, and in turn, the correlation with the highest percentage of error is that of Petrosky \& Farshad.

Figure 10 shows the relationship between pressure and the empirical correlations of the GOR property, according to the estimation parameters of the correlations. The \%AARE indicates the degree of approximation, where $33.54 \%$ is the closest approximation (Standing), and $107.11 \%$ is the furthest approximation (Petrosky \& Farshad). Therefore, the Standing correlation is close to the laboratory test results, unlike the Petrosky \& Farshad correlation, which is far from the laboratory results.

\subsubsection{Oil volumetric factor}

Table 6 shows the results of the correlations reported by PVTTESTSYSTEM. The\% AARE of each of the empirical correlations presented, giving the lowest\% AARE that of the Al-Marhoun correlation, different from the Glaso correlation with the highest percentage of error.

Figure 11 shows the relationship between the pressure and the empirical correlations of the oil's volumetric factor property, according to the estimation parameters of the correlations. The \%AARE indicates the closest approximation (Al-Marhoun, 2.88\%) and the furthest approximation (Glaso, $4.04 \%$ ). Therefore, the Al-Marhoun correlation is close to the laboratory test results, different from Glaso's correlation which is far from the laboratory results.
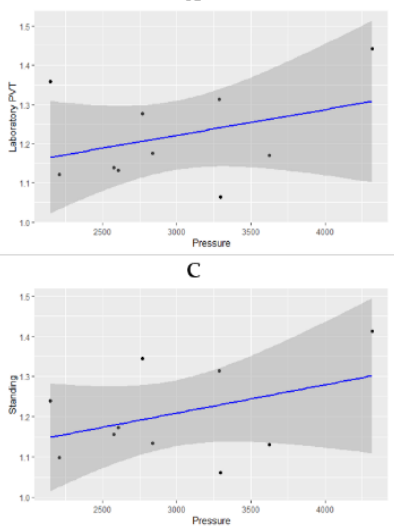
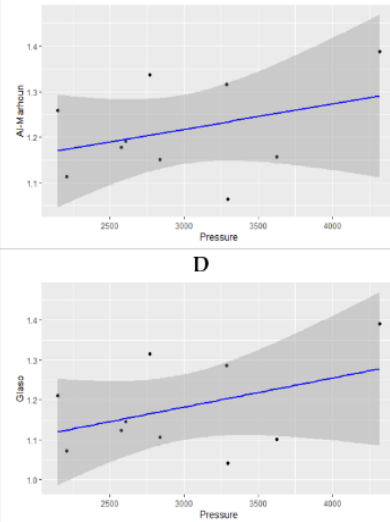

Figure 11. Oil pressure and volumetric factor relationship. (A) Laboratory test; (B) Al-Marhoun correlation; (C) Standing correlation; (D) Glaso correlation

Table 5. GOR properties correlation results

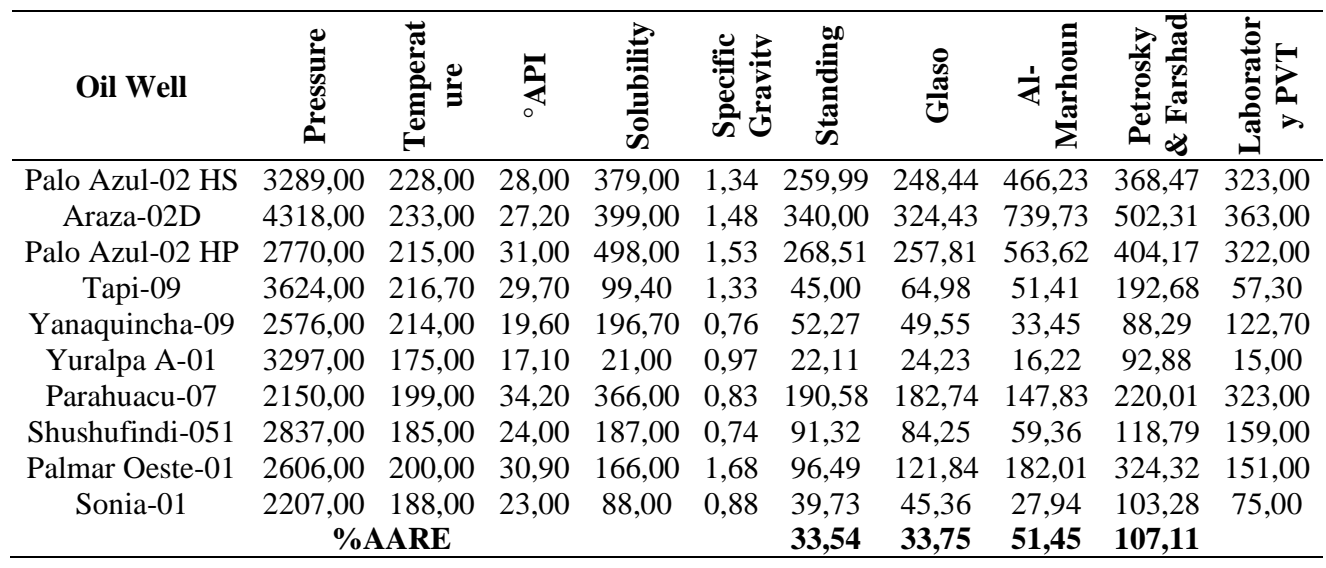


Table 6. Correlations volumetric factor properties oil

\begin{tabular}{|c|c|c|c|c|c|c|c|c|c|c|}
\hline Oil Well & 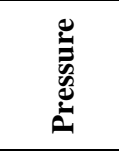 & 苞 & $\sum_{0}^{2}$ & 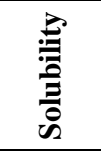 & 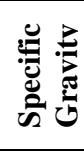 & 㲵 & 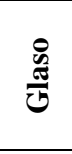 & 文吾 & 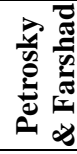 & 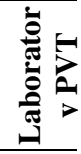 \\
\hline Palo Azul-02 HS & 3289,00 & 228,00 & 28,00 & 379,00 & 1,34 & 1,31 & 1,29 & 1,32 & 1,35 & 1,31 \\
\hline Araza-02D & 4318,00 & 233,00 & 27,20 & 399,00 & 1,48 & 1,41 & 1,39 & 1,39 & 1,47 & 1,44 \\
\hline Palo Azul-02 HP & 2770,00 & 215,00 & 31,00 & 498,00 & 1,53 & 1,34 & 1,32 & 1,34 & 1,39 & 1,28 \\
\hline Tapi-09 & 3624,00 & 216,70 & 29,70 & 99,40 & 1,33 & 1,13 & 1,10 & 1,16 & 1,13 & 1,17 \\
\hline Yanaquincha-09 & 2576,00 & 214,00 & 19,60 & 196,70 & 0,76 & 1,16 & 1,12 & 1,18 & 1,14 & 1,14 \\
\hline Yuralpa A-01 & 3297,00 & 175,00 & 17,10 & 21,00 & 0,97 & 1,06 & 1,04 & 1,06 & 1,04 & 1,06 \\
\hline Parahuacu-07 & 2150,00 & 199,00 & 34,20 & 366,00 & 0,83 & 1,24 & 1,21 & 1,26 & 1,25 & 1,36 \\
\hline Shushufindi-051 & 2837,00 & 185,00 & 24,00 & 187,00 & 0,74 & 1,13 & 1,11 & 1,15 & 1,13 & 1,17 \\
\hline Palmar Oeste-01 & 2606,00 & 200,00 & 30,90 & 166,00 & 1,68 & 1,17 & 1,15 & 1,19 & 1,20 & 1,13 \\
\hline Sonia-01 & 2207,00 & 188,00 & 23,00 & 88,00 & 0,88 & 1,10 & 1,07 & 1,11 & 1,09 & 1,12 \\
\hline \multicolumn{6}{|c|}{ \%AARE } & $\mathbf{3 , 0 5}$ & 4,04 & 2,88 & $\mathbf{4 , 0 2}$ & \\
\hline
\end{tabular}

Table 7. Correlations compressibility properties of the oil

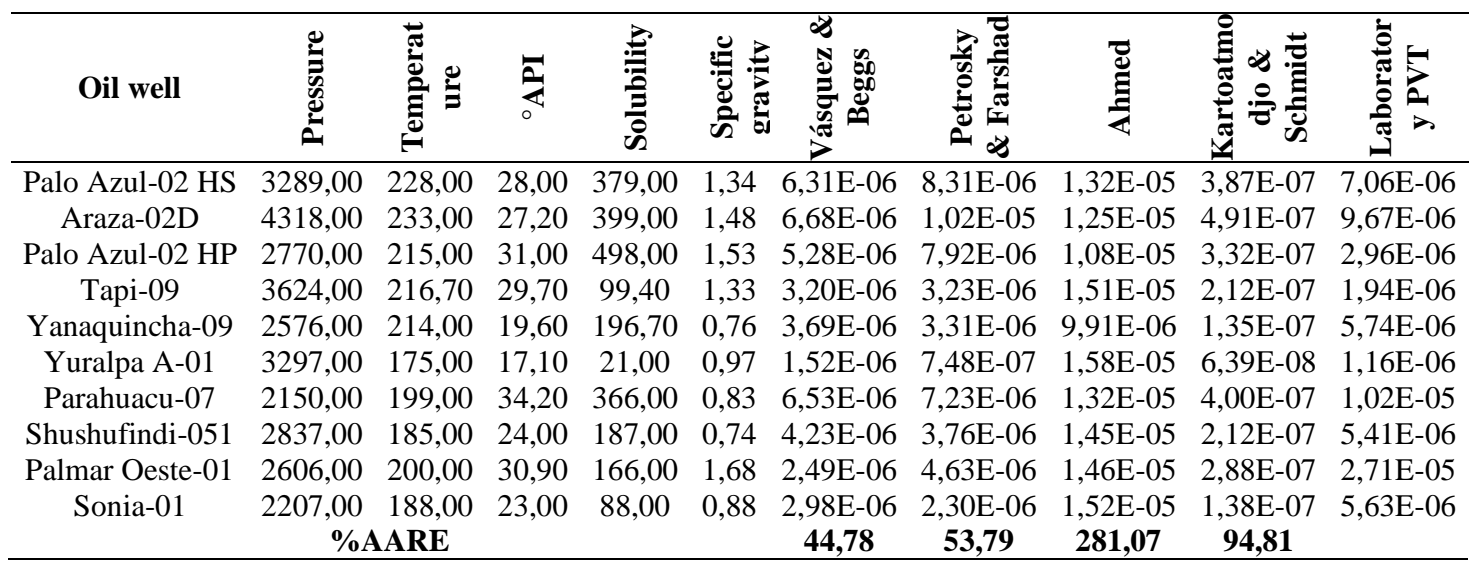

\subsubsection{Oil compressibility}

Table 7 shows the empirical correlations of oil compressibility and the laboratory tests under the initial conditions reported in Table 3. The Vásquez and Begs correlation correlate with the lowest percentage of error, whereas the correlation with the highest error percentage is Kartoatmodjo and Schmidt.

A
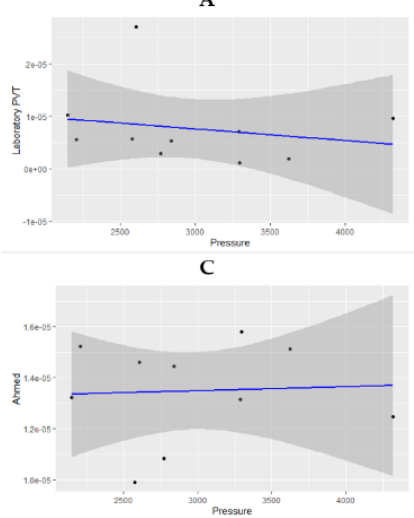

Figure 12. Relationship of pressure and compressibility of oil. (A) Laboratory test; (B) Vásquez and Beggs correlation;

(C) Ahmed correlation; (D) Kartoatmodjo and Schmidt correlation

The relationship between pressure and empirical correlations of the compressibility property of oil is shown in Figure 12. Based on the \%AARE of the correlations and the estimation parameters of the correlations, $44.78 \%$ close approximation and $281.07 \%$ distant approximation are determined, Vasquez and Beggs and Ahmed, respectively. Regarding the Vasquez and Beggs correlation, there is an approximation to the laboratory test results, different from the Ahmed correlation, with far data from the laboratory results.

\subsubsection{Dead oil viscosity}

The correlations by PVTTESTSYSTEM are shown in Table 8. The Kartoatmodjo and Schmidt correlation has the lowest error percentage, different from the Beal correlation, which has the highest error percentage.
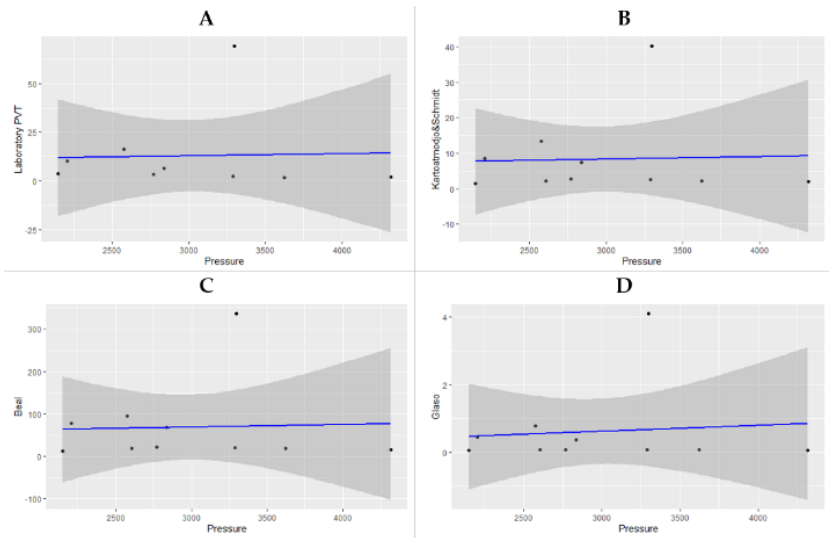

Figure 13. Pressure relationship of the viscosity of unsaturated oil. (A) Laboratory test; (B) Kartoatmodjo and Schmidt correlation; (C) Beal's correlation. (D) Glaso correlation 
The relationship between pressure and empirical correlations of dead oil viscosity showed in Figure 13, thus identifying the Kartoatmodjo and Schmidt correlation $(19.56 \%)$ as the correlation that is close to the laboratory test results, different from the Beal correlation $(556.23 \%)$ that is far from the laboratory results.

\subsubsection{Viscosity saturate oil}

PVTTESTSYSTEM reports the results of the correlations of the viscosity properties of saturated oil in Table 9. The error percentages of each of the empirical correlations presented; the lowest percentage belongs to the Chew and Connally correlation. In contrast, the correlation of Almehaideb has the highest error rate.

Table 8. Correlations viscosity properties of dead oil

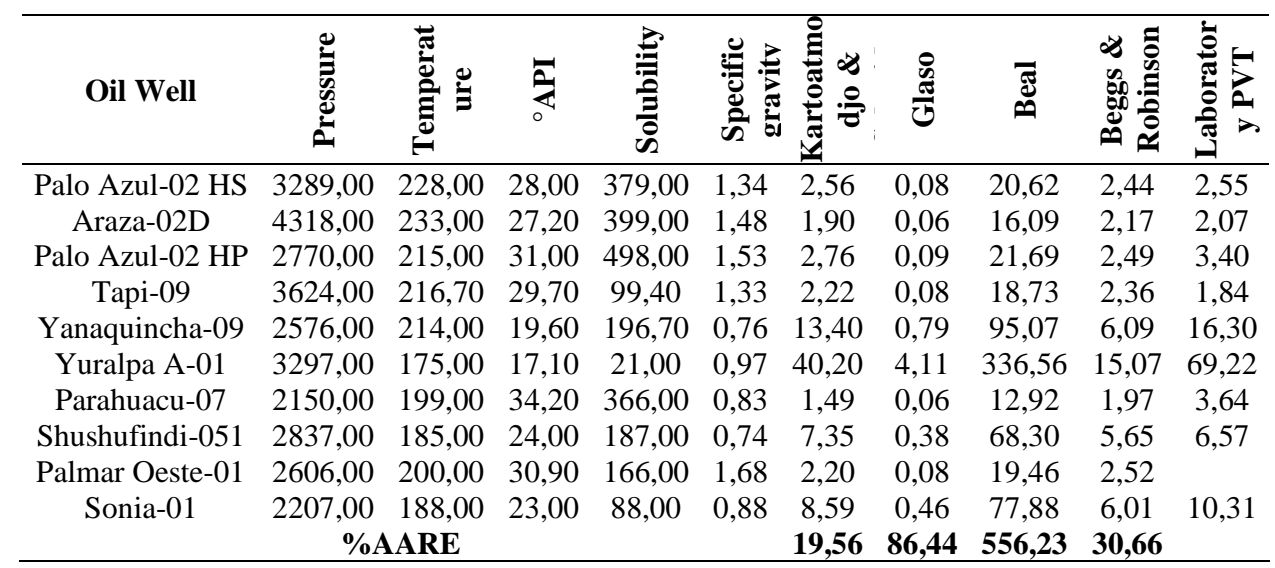

Table 9. Correlations viscosity properties saturate oil

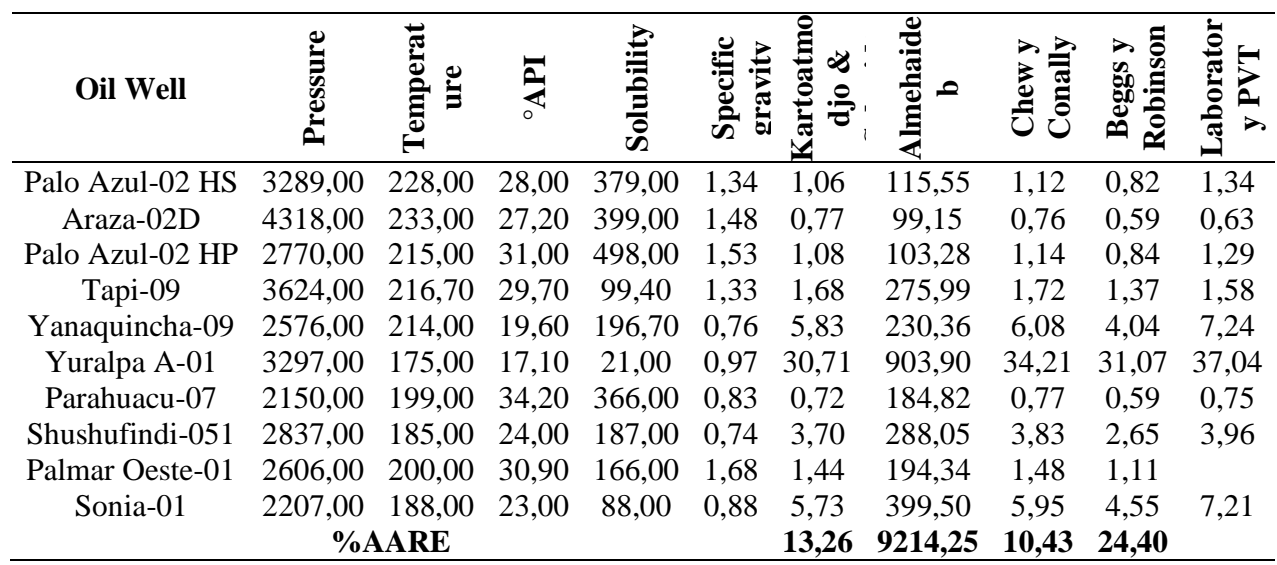

Table 10. Correlations gas compressibility factor

\begin{tabular}{|c|c|c|c|c|c|c|c|c|c|c|}
\hline Oil Well & 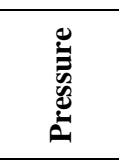 & D & $\sum_{0}^{\mathbb{Z}}$ & 章 & 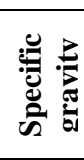 & 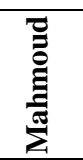 & 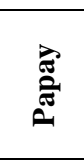 & 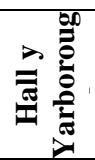 & 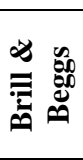 & 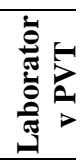 \\
\hline Palo Azul-02 HS & 3289,00 & 228,00 & 28,00 & 379,00 & 1,34 & 0,73 & 0,75 & 0,91 & 1,09 & 0,89 \\
\hline Araza-02D & 4318,00 & 233,00 & 27,20 & 399,00 & 1,48 & 0,52 & 0,58 & 0,83 & 1,10 & 0,31 \\
\hline Palo Azul-02 HP & 2770,00 & 215,00 & 31,00 & 498,00 & 1,53 & 0,59 & 0,64 & 0,86 & 1,11 & 0,84 \\
\hline Tapi-09 & 3624,00 & 216,70 & 29,70 & 99,40 & 1,33 & 0,93 & 0,92 & 0,97 & 1,03 & 0,82 \\
\hline Yanaquincha-09 & 2576,00 & 214,00 & 19,60 & 196,70 & 0,76 & 0,94 & 0,94 & 0,98 & 1,05 & 0,91 \\
\hline Yuralpa & 3297,00 & 175,00 & 17,10 & 21,00 & 0,97 & 0,96 & 0,95 & 0,98 & 1,02 & 0,99 \\
\hline Parahı & 2150,00 & 199,00 & 34,20 & 366,00 & 0,83 & 0,97 & 0,97 & 0,97 & 1,02 & 0,89 \\
\hline Shushu & 2837,00 & 185,00 & 24,00 & 187,00 & 0,74 & 0,91 & 0,92 & 0,92 & 1,07 & 0,92 \\
\hline Palmar & 2606,00 & 200,00 & 30,90 & 166,00 & 1,68 & 0,80 & 0,81 & 0,93 & 1,03 & 0,80 \\
\hline Sonia-01 & 2207,00 & 188,00 & 23,00 & 88,00 & 0,88 & 0,94 & 0,94 & 0,98 & 1,04 & 0,98 \\
\hline \multicolumn{11}{|c|}{ \%AARE } \\
\hline
\end{tabular}

Figure 14 shows the relationship between pressure and empirical correlations of the saturated oil's viscosity property. Thus, the correlation of Chew and Connally (10.43\%) is close to the laboratory test results, while the correlation of Almehaideb (92-14.25\%) is far from the laboratory results.

\subsubsection{Gas compressibility factor}

The results reported by PVTTESTSYSTEM corresponding to the gas compressibility factor property shown in Table 10. They project the error percentages of each of the empirical correlations, thus obtaining the Mahmoud correlation's lowest 
percentage. The highest percentage of error is presented by the Brill and Beggs correlation.

Therefore, the relationship between pressure and the empirical correlations of the gas compressibility factor property is shown in Figure 15. An example is Mahmoud's correlation which has a \%AARE of $14.96 \%$ due to its estimation parameters, the correlation is close to the laboratory test results, while Brill and Beggs' correlation with \%AARE of $42.07 \%$ is far from the laboratory results. This case occurs because Mahmoud's estimation parameters used characterised by reduced pressures, and Brill and Begs use pseudoreduced pressures.
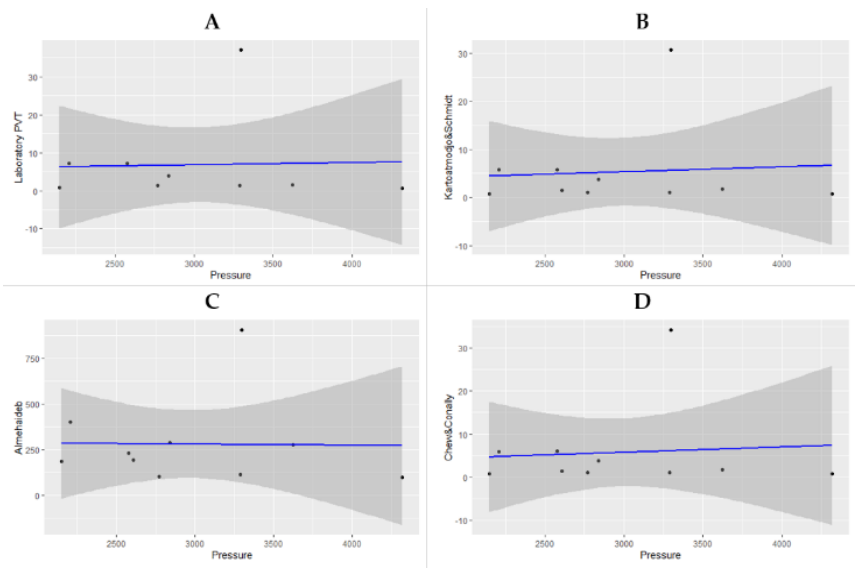

Figure 14. Pressure relationship and empirical correlations saturated oil viscosity. (A) Laboratory test; (B) Kartoatmodjo and Schmidt correlation; (C) Almehaideb correlation; (D) Chew and Connally correlation
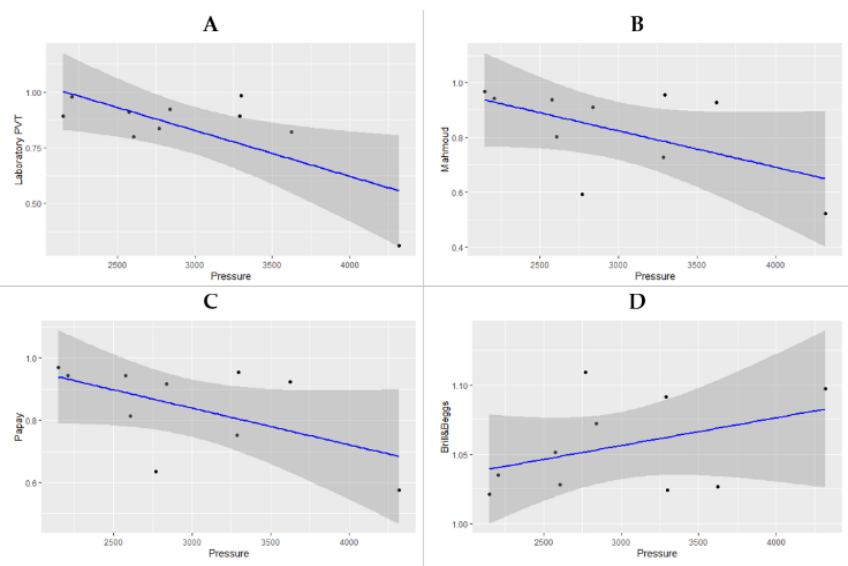

Figure 15. Pressure relationship and correlations of the gas compressibility factor. (A) Laboratory test; (B) Mahmoud correlation; (C) Papay correlation, (D) Brill and Beggs correlation

\subsection{PVTTESTSYSTEM algorithm's confidence level}

The empirical software values report close approximations to the experimental values from the PVT tests. These values have a strong relationship concerning the initial conditions of the oil wells and the laboratory tests, a relationship measured by correlation coefficients. The application results are evaluated with a significance of $95 \%$, thus achieving a confidence level of $85.15 \%$ of the algorithm. Table 11 shows the respective parameters that establish the algorithm's confidence interval, significance level, and confidence level [58].
Table 11. PVTTESTSYSTEM algorithm's confidence level.

\begin{tabular}{cc}
\hline Statistics & Values \\
\hline Standard deviation & 0,311397984 \\
Significance level & 0,95 \\
Confidence interval & 0,074250228 \\
Confidence level & $85,15 \%$ \\
\hline
\end{tabular}

\section{DISCUSSION}

The structure of the PVTTESTSYSTEM algorithm proposes an optimal workflow through the input of initial characteristics of oil wells of any reservoir, reflecting an interactive, modifiable and applicable application. The proposed computer application improves the accessibility of large amounts of information in the entry of data from oil wells, oil fields, oil companies and PVT correlations, guaranteeing efficient computer management at the time of determining the background of any reservoir, avoiding duplication of data and improving the security of information, unlike spreadsheets limited and straightforward search of PVT data [37].

The results reported by PVTTESTSYSTEM are easy to interpret and applicable to a statistic based on the analysis of the relationship between the correlations of the properties concerning the initial conditions of the oil well, determining approximations to reality through the error percentages, as shown in Tables 4-10 [1, 59-61]. In addition, there is the proximity between experimental (laboratory tests) and estimations (empirical correlations), where it shows approximate or non-approximate correlations to laboratory tests (Figures 9-15). To ensure approximation, each correlation parameter is systematized and validated, such as wells' pressure and temperature, depending on ranges of values for each property, correlation and petroleum region [7, 46]. For example, Libyan crudes with pressure from 128 to 6344 PSI, temperature from 100 to $313^{\circ} \mathrm{F}$ and ${ }^{\circ} \mathrm{API}$ from 26 to 51 present a better fit in bubble pressure through a new correlation Standing, Vasquez and Begs, and Khazam [12]. Another case is Sudanese crudes with pressure from 90 to 1985 PSI, temperature from 133 to $244{ }^{\circ} \mathrm{F}$ and ${ }^{\circ} \mathrm{API}$ from 18.87 to 39.6 with same bubble pressure, presents a better fit and a new correlation based on Farshad, Al-Shammasi, and Vasquez and Begs [32]. The study is oriented to parameters set out in Table 3 (pressure from 2150 to 4318 psi, temperature from 175 to $233{ }^{\circ} \mathrm{F}$ and ${ }^{\circ} \mathrm{API}$ from 17.10 to 34.20 ), using existing correlations with an option to enter new correlations, reports its best approximation with Dokla and Osman.

Other PVT simulators, such as PVT SIM [21], have a commercial interface, IntelliPVT simulator with a basic graphical interface [25], different from the open and accessible interface of PVTTESTSYSTEM, different from the office interface of macros made in Excel [7, 59].

Some tools do not have input and storage of information related to the reservoir's history [37, 62], unlike PVTTESTSYSTEM, which records customised characteristics for any given reservoir.

Some applications used in PVT analysis lack data storage management [7, 37, 62]; whereas, PVTTESTSYSTEM has a database that stores large amounts of data, similar to the PVTSIM tool that used a voluminous database in the study of oil and gas behaviour in the Norwegian North Sea [20].

Although other PVT simulators, developed in Trademark and Excel [7, 62], numerical project results of correlations, PVTTESTSYSTEM graphically sizes comparisons between 
initial well characteristics and the behaviour.

Results reported by the study of oil fields in southern Algeria, specifically with the Hassi Messaoud oil field, as well as the PVT analysis of oil fields in Nigeria (Delta Niger), coincide with the results of the correlations in this study due to their similar initial conditions for the petroleum fluids [2, $15]$.

Regarding the correlations used in this study: Standing (used to predict the bubble pressure property and the GOR property); Vasquez and Begs (which predicts the compressibility property of the oil); Chew and Connally (estimates the viscosity of saturated oil); it has been determined that these correlations reported by PVTTESTSYSTEM, present significantly similar results to the study carried out in the Gulf of Mexico crudes, where bubble pressure, GOR and compressibility properties were determined [7].

\section{CONCLUSIONS}

PVTTESTSYSTEM is a computer application designed using a consistent PVT simulation algorithm, which predicts oil properties' behaviour in an oil field, approaching experimental results. PVTTESTSYSTEM is a computer application designed using a consistent PVT simulation algorithm, which predicts oil properties' behaviour in an oil field, approaching experimental results. In addition, it has a large-volume database for storing empirical correlations, supporting reservoir characterization procedures, contributing to oil exploration decision-making. The study applied data from eastern Ecuador's ten oil wells, obtaining approximation results in the upper quartile between the experimental field values, with values calculated by the computer tool designed.

The difference between the PVTTESTSYSTEM and experimental results, about the correlations, were: $5 \%$ for bubble pressure, $26.4 \%$ for GOR property, $0.3 \%$ volumetric factor of oil, $44 \%$ for oil compressibility, 30, 6\% for dead oil viscosity, $8.9 \%$ for saturated oil viscosity and $0.6 \%$ for gas compressibility factor. These results are acceptable for each correlation's AARE percentages, indicating that PVT properties can be accurately estimated using this software.

PVTTESTSYSTEM allows the entry of different initial conditions from other oil basins that adjust to the correlations proposed in the literature or calculated on the software platform. This factor is vital in the calculation criteria of the PVT correlations since the natural environments of oil fields are diverse due to the fluid's conditions and characteristics. Therefore, it is convenient to perform various calculations with different correlations to select the best settings.

\section{ACKNOWLEDGMENT}

This research study was possible of the "Design of software for the analysis of PVT of black oil" academic research project by UPSE University, and support of Best Energy S. and Aand CIPAT-ESPOL.

\section{REFERENCES}

[1] El-Sebakhy, E.A. (2009). Data mining in forecasting PVT correlations of crude oil systems based on Type1 fuzzy logic inference systems. Computers \& Geosciences, 35(9): 1817-1826. https://doi.org/10.1016/j.cageo.2007.10.016

[2] Ikiensikimama, S.S., Ajienka, J.A. (2012). Impact of PVT correlations development on hydrocarbon accounting: the case of the Niger Delta. Journal of Petroleum Science and Engineering, 81: 80-85. https://doi.org/10.1016/j.petrol.2011.12.017

[3] Mansour, E.M., Farag, A.B., El-Dars, F.S., Desouky, S.M., Batanoni, M.H., Mahmoud, M.R.M. (2013). Predicting PVT properties of Egyptian crude oils by a modified Soave-Redlich-Kowng equation of state. Egyptian Journal of Petroleum, 22(1): 137-148. https://doi.org/10.1016/j.ejpe.2012.09.005

[4] Ramirez, A.M., Valle, G.A., Romero, F., Jaimes, M. (2017). Prediction of PVT properties in crude oil using machine learning techniques MLT. In SPE Latin America and Caribbean Petroleum Engineering Conference. OnePetro. https://doi.org/10.2118/185536MS.

[5] Nabipour, N., Baghban, A. (2019). Rigorous model for determination of PVT properties of crude oil in operational conditions. Energy Sources, Part A: Recovery, Utilization, and Environmental Effects, pp. 17. https://doi.org/10.1080/15567036.2019.1677823

[6] Di Primio, R., Dieckmann, V., Mills, N. (1998). PVT and phase behaviour analysis in petroleum exploration. Organic Geochemistry, 29(1-3): 207-222. https://doi.org/10.1016/S0146-6380(98)00102-8

[7] Dindoruk, B., Christman, P.G. (2001). PVT properties and viscosity correlations for Gulf of Mexico oils. In SPE Annual Technical Conference and Exhibition. OnePetro. https://doi.org/10.2118/71633-MS

[8] Gaganis, V., Kourlianski, E., Varotsis, N. (2017). An accurate method to generate composite PVT data for black oil simulation. Journal of Petroleum Science and Engineering, 157: 1-13. https://doi.org/10.1016/j.petrol.2017.07.006

[9] Aybeniz, A. (2018). Current Approaches in Prediction of PVT Properties of Reservoir Oils. Review of Information Engineering and Applications, 5(2): 31-40. https://doi.org/10.18488/journal.79.2018.52.31.40

[10] Rammay, M.H., Abdulraheem, A. (2017). PVT correlations for Pakistani crude oils using artificial neural network. Journal of Petroleum Exploration and Production Technology, 7(1): 217-233. https://doi.org/10.1007/s13202-016-0232-z

[11] Sola-Aremu, O. (2019). An inferable machine learning approach to predicting PVT properties of Niger delta crude oil using compositional data. In SPE Annual Technical Conference and Exhibition. OnePetro. https://doi.org/10.2118/199783-STU

[12] Khazam, M., Alkhaboli, M., Shlak, M. (2016). New PVT correlations for Libyan crudes. ICCPGE, 1: 25-30.

[13] Ladopoulos, E.G. (2019). Oil \& gas reserves in the absence of PVT analysis for the estimation of bubblepoint. Univers, Journals Hydraul, 7: 15-21.

[14] Liu, Y., Yuan, Y., Zhou, F., Qi, Z., Zhang, W., Zhang, H., Wang, Q. (2020). Analysis on PVT test and empirical formula of Bohai heavy oil with different types of dissolved gases. Journal of Petroleum Exploration and Production Technology, 10(8): 3609-3617. https://doi.org/10.1007/s13202-020-00973-7

[15] Sidrouhou, H.M., Korichi, M. (2013). Empirical and 
correlative study of PVT proprieties of Algerian oil. Energy Procedia, 36: 738-745. https://doi.org/10.1016/j.egypro.2013.07.086

[16] Ireke, I.U., Princewill, M.I. (2017). Impact of PVT correlations on reserve estimation: Reliability and qualitative analysis. In SPE Nigeria Annual International Conference and Exhibition. OnePetro. https://doi.org/10.2118/189165-MS

[17] Oloso, M.A., Hassan, M.G., Bader-El-Den, M.B., Buick, J.M. (2017). Hybrid functional networks for oil reservoir PVT characterisation. Expert Systems with Applications, 87: 363-369. https://doi.org/10.1016/j.eswa.2017.06.014

[18] El-hoshoudy, A.N. (2019). Production Department, Egyptian Petroleum Research Institute, Naser City, Cairo, Egypt. Pet, Coal Pet, 61(6): 1282-1299.

[19] Almehaideb, R.A., Al-Khanbashi, A.S., Abdulkarim, M., Ali, M.A. (2000). EOS tuning to model full field crude oil properties using multiple well fluid PVT analysis. Journal of Petroleum Science and Engineering, 26(1-4): 291-300. https://doi.org/10.1016/S0920-4105(00)000437

[20] Aplin, A.C., Macleod, G., Larter, S.R., Pedersen, K.S., Sorensen, H., Booth, T. (1999). Combined use of Confocal Laser Scanning Microscopyand PVT simulation for estimating the composition andphysical properties of petroleum in fluid inclusions. Marine and Petroleum Geology, 16(2): 97-110. https://doi.org/10.1016/S0264-8172(98)00079-8

[21] Liu, D.H., Xiao, X.M., Mi, J.K., Li, X.Q., Shen, J.K., Song, Z.G., Peng, P.A. (2003). Determination of trapping pressure and temperature of petroleum inclusions using PVT simulation software - A case study of Lower Ordovician carbonates from the Lunnan Low Uplift, Tarim Basin. Marine and Petroleum Geology, 20(1): 2943. https://doi.org/10.1016/S0264-8172(03)00047-3

[22] Hassanzadeh, H., Pooladi-Darvish, M., Elsharkawy, A.M., Keith, D.W., Leonenko, Y. (2008). Predicting PVT data for $\mathrm{CO}_{2}$-brine mixtures for black-oil simulation of $\mathrm{CO}_{2}$ geological storage. International Journal of Greenhouse Gas Control, 2(1): 65-77. https://doi.org/10.1016/S1750-5836(07)00010-2

[23] Valle Tamayo, G.A., Romero Consuegra, F., Mendoza Vargas, L.F., Osorio Gonzalez, D.A. (2017). Empirical PVT correlations applied for colombian crude oils: A new approach. In SPE Latin America and Caribbean Petroleum Engineering Conference. OnePetro. https://doi.org/10.2118/185565-MS

[24] Uzogor, K., Akinsete, O. (2020). Improved correlations and predictive models for Nigerian crude oil PVT properties using advanced regression and intelligent techniques. In SPE Nigeria Annual International Conference and Exhibition. OnePetro. https://doi.org/10.2118/203658-MS

[25] Olatunji, O., Mogbolu, J. (2020). A novel algorithmic design and implementation for predicting Crude-Oil PVT properties. In SPE Nigeria Annual International Conference and Exhibition. OnePetro. https://doi.org/10.2118/203716-MS

[26] Alamir, Á.L.; Gricelda, H.F., Karla, E.M. (2015). La Libertad. UPSE, Matríz. Facultad Ciencias de la Ingeniería.

[27] Espinoza, V.S., Fontalvo, J., Martí-Herrero, J., Ramírez, P., Capellán-Pérez, I. (2019). Future oil extraction in Ecuador using a Hubbert approach. Energy, 182: 520-
534. https://doi.org/10.1016/j.energy.2019.06.061

[28] Taber, P. (2020). Environmental consulting as experimental system: Uncertainty and emergence in Ecuador's oil sector, 1988-2001. Geoforum, 108: 88-97. https://doi.org/10.1016/j.geoforum.2019.12.001

[29] Asadisaghandi, J., Tahmasebi, P. (2011). Comparative evaluation of back-propagation neural network learning algorithms and empirical correlations for prediction of oil PVT properties in Iran oilfields. Journal of Petroleum Science and Engineering, 78(2): 464-475. https://doi.org/10.1016/j.petrol.2011.06.024

[30] Al-Marhoun, M.A. (2004). Evaluation of empirically derived PVT properties for Middle East crude oils. Journal of Petroleum Science and Engineering, 42(2-4): 209-221. https://doi.org/10.1016/j.petrol.2003.12.012

[31] Godefroy, S.N., Khor, S.H., Emms, D. (2012). Comparison and validation of theoretical and empirical correlations for black oil reservoir fluid properties. Offshore Technology Conference. https://doi.org/10.4043/22972-MS

[32] Mohamed, A., Ahmed, M., Mohamed, I., Abdein, M. (2018). The performance of the popular PVT correlations on Sudanese crude oils: A statistical study. In SPE Kingdom of Saudi Arabia Annual Technical Symposium and Exhibition. OnePetro. https://doi.org/10.2118/192438-MS

[33] El-Banbi A., Alzahabi A., El-Maraghi A. (2018). Selection of PVT Correlations. PVT Property Correlations, Elsevier, pp. 203-224

[34] Standing, M.B. (1947). A pressure-volume-temperature correlation for mixtures of California oils and gases. In Drilling and Production Practice. OnePetro.

[35] Petrosky, G.E., Farshad, F.F. (1993). Pressure-volumetemperature correlations for Gulf of Mexico crude oils. SPE Annual Technical Conference and Exhibition, Houston, Texas. https://doi.org/10.2118/26644-MS

[36] Lasater, J.A. (1958). Bubble point pressure correlation. Society of Petroleum Engineers, 10(5): 65-67. https://doi.org/10.2118/957-G

[37] Kanu, A.U., Ikiensikimama, S.S. (2014). Globalization of black oil PVT correlations. SPE Nigeria Annual International Conference and Exhibition, Lagos, Nigeria. https://doi.org/10.2118/172494-MS

[38] Glaso, O. (1980). Generalized pressure-volumetemperature correlations. Society of Petroleum Engineers. 32(5): 785-795. https://doi.org/10.2118/8016-PA

[39] Al-Marhoun, M.A. (1988). PVT correlations for middle east crude oils. Society of Petroleum Engineers, 40(5): 650-666. https://doi.org/10.2118/13718-PA

[40] Dokla, M., Osman, M. (1992). Correlation of PVT Properties for UAE Crudes (includes associated papers 26135 and 26316). SPE formation evaluation, 7(1): 4146. https://doi.org/10.2118/20989-PA

[41] Velarde, J., Blasingame, T.A., McCain, W.D. (1997). Correlation of black oil properties at pressures below bubble point pressure - A new approach. Annual Technical Meeting, Calgary, Alberta. https://doi.org/10.2118/97-93

[42] Al-Marhoun, M.A. (1992). New correlations for formation volume factors of oil and gas mixtures. Petroleum Society of Canada, 31(3). https://doi.org/10.2118/92-03-02

[43] Vasquez, M., Beggs, H.D. (1980). Correlations for fluid physical property prediction. Society of Petroleum 
Engineers, 32(6): 968-970. https://doi.org/10.2118/6719PA

[44] Ahmed, T. (2010). Reservoir Engineering Handbook (Fourth Edition), Gulf Professional Publishing. Page iv, https://doi.org/10.1016/B978-1-85617-803-7.50001-8

[45] Kartoatmodjo, T., Schmidt, Z. (1991). New correlations for crude oil physical properties. Society of Petroleum Engineers, pp. 1-39.

[46] Al-Zahaby, A., El-Banbi, A., Sayyouh, M.H. (2012). Guidelines for selecting appropriate PVT correlations for black oils. In North Africa Technical Conference and Exhibition. OnePetro. https://doi.org/10.2118/150650MS

[47] Beal, C. (1946). The viscosity of air, water, natural gas, crude oil and its associated gases at oil field temperatures and pressures. Transactions of the AIME, 165(1): 94-115. https://doi.org/10.2118/946094-G

[48] Beggs, H.D., Robinson, J. (1975). Estimating the viscosity of crude oil systems. Journal of Petroleum technology, 27(9): 1140-1141. https://doi.org/10.2118/5434-PA

[49] Chew, J.N., Connally, C.A. (1959). A viscosity correlation for gas-saturated crude oils. Transactions of the AIME, 216(1): 23-25. https://doi.org/10.2118/1092$\mathrm{G}$

[50] Almehaideb, R.A. (1997). Improved PVT correlations for UAE crude oils. In Middle East Oil Show and Conference. OnePetro. https://doi.org/10.2118/37691MS

[51] Lee, A.L., Gonzalez, M.H., Eakin, B.E. (1966). The viscosity of natural gases. Journal of Petroleum Technology, $\quad$ 18(8): $\quad 997-1000$ https://doi.org/10.2118/1340-PA

[52] Londono, F.E., Archer, R.A., Blasingame, T.A. (2005). Correlations for hydrocarbon gas viscosity and gas density-validation and correlation of behavior using a large-scale database. SPE Reservoir Evaluation \& Engineering, $\quad 8(6)$ : $561-572$. https://doi.org/10.2118/75721-MS

[53] Banzer, C. (1996). Correlaciones numéricas PVT, edición preliminar; Instituto de investigaciones petroleras de la Universidad de Zulia, pp. 1-133.

[54] Ilinova, A., Chanysheva, A. (2020). Algorithm for assessing the prospects of offshore oil and gas projects in the Arctic. Energy Reports, 6: 504-509. https://doi.org/10.1016/j.egyr.2019.11.110

[55] Bristone, M., Prasad, R., Abubakar, A.A. (2019). CPPCNDL: Crude oil price prediction using complex network and deep learning algorithms. Petroleum, 6(4):

353-361. https://doi.org/10.1016/j.petlm.2019.11.009

[56] Wakefield, C., Sonder, H.E., Lee, W.M. (2001). Chapter 14 - upgrading visual basic applications to NET. In VB. Net Developer's Guide, pp. 647-712. https://doi.org/10.1016/B978-192899448-0/50019-7

[57] Fotache, M., Strimbei, C. (2015). SQL and data analysis. Some implications for data analysis and higher education. Procedia Economics and Finance, 20: 243-251. https://doi.org/10.1016/S2212-5671(15)00071-4

[58] Zhang, K., Chen, H., Yang, Z., Duan, Y. (2020). Experimental PVT property for the liquid HFO1234ze (E) using the isochoric method. The Journal of Chemical Thermodynamics, 149: 106160. https://doi.org/10.1016/j.jct.2020.106160

[59] Izurieta, A.J., Iza, A. (2017). The PVT properties of the Ecuadorian crude oils. In SPE Latin America and Caribbean Petroleum Engineering Conference. OnePetro. https://doi.org/10.2118/185483-MS

[60] Fattah, K.A. (2012). K-value program for crude oil components at high pressures based on PVT laboratory data and genetic programming. Journal of King Saud University-Engineering Sciences, 24(2): 141-149. https://doi.org/10.1016/j.jksues.2011.06.002

[61] Elkatatny, S., Moussa, T., Abdulraheem, A., Mahmoud, M. (2018). A self-adaptive artificial intelligence technique to predict oil pressure volume temperature properties. $\quad$ Energies, $11(12)$ : 3490. https://doi.org/10.3390/en11123490

[62] Singh, T., Hosein, R. (2012). PVT Correlation for Trinidad oil the offshore southwest coast. In SPETT 2012 Energy Conference and Exhibition, Port-of-Spain, Trinidad. https://doi.org/10.2118/158805-MS

\section{NOMENCLATURE}

PVT

GOR

$\mathrm{PCN} / \mathrm{BN}$

$\mathrm{BY} / \mathrm{BN}$

Psi

${ }^{\circ} \mathrm{F}$

${ }^{\circ} \mathrm{API}$

$\mathrm{SCF} / \mathrm{STB}$

$\%$ AARE

PVTTESTSYSTEM PVT testing system pressure, volume and temperature gas-oil ratio normal cubic feet / normal barrels reservoir barrels / normal barrels pounds per square inch Fahrenheit degrees American petroleum institute standard cubic foot per stock tank barrel percentage of absolute average error 